\title{
Principais inovações e perspectivas da nova Lei de Migrações
}

\author{
Principales innovaciones y perspectivas de la nueva Ley de Migración \\ Main innovations and perspectives of the new Migration Law
}

Carla Campos Avanzi ${ }^{1}$

Aristeu Matias Simon²

\begin{abstract}
Resumo
O debate sobre a situação dos imigrantes e as suas perspectivas perante o Estado em que são acolhidos passa necessariamente pela legislação em vigor sobre o tema. A nova Lei de Migrações, com texto final aprovado pelo Congresso Nacional em 18 de abril de 2017, representa grande avanço social ao oferecer maiores garantias aos migrantes, consagrando a dignidade da pessoa humana e deixando de tratar o tema como uma questão exclusivamente de segurança pública, como ocorria com o antigo Estatuto do Estrangeiro. O presente estudo visa elencar as principais mudanças trazidas pela nova Lei de Migrações, evidenciando uma mudança de perspectiva do Estado com relação aos migrantes, e destacar como essas mudanças contribuíram para o fortalecimento dos direitos humanos no Brasil.
\end{abstract}

Palavras-Chave: Migração; legislação; direitos humanos; segurança pública.

\section{Resumen}

El debate sobre la situación de los inmigrantes y sus perspectivas ante el Estado para su acogida implica necesariamente la legislación sobre la materia. La nueva Ley de migración, con el texto final aprobado por el Congreso el 18 de abril de 2017, representa un gran progreso social ofreciendo mayores garantías a los migrantes, que consagra la dignidad de la persona humana y no abordar el tema como un asunto exclusivamente para la seguridad pública como ocurrió con el anterior Estatuto de Extranjero. Este estudio tiene como objetivo recopilar los principales cambios introducidos por la nueva Ley de Migración, que muestra un cambio de estado del punto de vista con respecto a los migrantes, y poner de relieve cómo estos cambios han contribuido al fortalecimiento de los derechos humanos en Brasil.

Palabras claves: Migración; legislación; derechos humanos; Seguridad Pública.

\footnotetext{
Abstract

${ }^{1}$ Especialista em Direito Constitucional Contemporâneo, Instituto de Direito Constitucional e Cidadania - IDCC; Graduanda em Ciências Sociais; Universidade Estadual de Londrina - UEL; Londrina, Paraná, Brasil; e-mail: carla_avanzi@hotmail.com.

${ }^{2}$ Especialização em Gestão Industrial e Negócios, graduando em Relações Públicas; Universidade Estadual de Londrina - UEL; Londrina, Paraná, Brasil; e-mail: aristeu.simon@gmail.com.
} 
The debate on a situation of immigrants and how their prospects vis-a-vis the State in which they are received necessarily pass through the legislation in force on the subject. The new Migration Law, with the final text approved by the National Congress on April 18, 2017, represents a great social advance by offering greater guarantees to migrants, consecrating the dignity of the human person and leaving the issue as a matter exclusively of public security As was the case with the former Foreigner Statute. The present study aims to highlight the main changes brought about by a new Migration Law, highlighting a change in the state's perspective on migrants, and to highlight how to contribute to the strengthening of human rights in Brazil.

Keywords: Migration; legislation; human rights; public security

\section{Contextualização - $O$ antigo estatuto do estrangeiro e a mudança de perspectiva do Estado}

A nova lei de Migrações, aprovada no Senado no dia 18/04/2017 e encaminhada para sanção presidencial representa um importante passo na proteção dos direitos humanos no Brasil, principalmente face às inúmeras pautas conservadoras e opressoras que vêm ganhando destaque no Congresso Nacional nos últimos anos.

Os novos conflitos mundiais, bem como as novas dinâmicas das relações pessoais e comerciais fizeram emergir a necessidade de uma moderna regulamentação que atendesse satisfatoriamente às recentes demandas sociais. Esta regulamentação, como não poderia ser diferente, sofreu grandes resistências dos representantes mais conservadores do Congresso Nacional, principalmente em virtude do conflito do debate com questões de segurança pública, bem como da análise da capacidade do Estado em atender às reivindicações de serviços públicos de todos que dele necessitam

No entanto, em que pesem as diversas modificações no texto e os protestos de alguns parlamentares que acreditam que a nova lei comprometeria a segurança nacional, a exemplo das declarações do senador Ronaldo Caiado em sua rede social, a proposta foi aprovada. Com isso, a legislação atual entra em consonância com as novas diretrizes doutrinárias sobre o tema, que reconhecem que a questão da migração perpassa o embate da segurança pública, tratando-se de um pleito de direitos humanos que merece atenção especial face à nova conjuntura global.

A nova lei revoga o Estatuto do Estrangeiro, criado em 1980, e traz elementos mais condizentes com a Constituição Federal promulgada em 1988, na medida em que abarca mais garantias aos migrantes, contemplando a dignidade da pessoa humana, principio tão consagrado pela carta constitucional. $\mathrm{O}$ antigo Estatuto foi sancionado em um contexto de ditadura militar no Brasil, e Guerra Fria no âmbito mundial, em que os estrangeiros, tanto internacionais quanto nacionais, eram vistos como inimigos da soberania do Estado. (SPRANDEL, 2015). Nesse contexto os meios de comunicação utilizados neste período propunham a sociedade a valorização do estado de suas posições sociais e da valorização de todo entorno cívico patriótico, para Pacheco (1970), a imprensa no período da ditadura manipulava e distorcia as informações, de forma que a construção do herói nacional poderia ser facilmente desenvolvida em detrimento da imagem do imigrante. Diante desta mudança de perspectiva com relação aos imigrantes, necessária se faz uma nova regulamentação sobre a matéria.

Insta salientar que o Estatuto do Estrangeiro, ainda que englobasse inúmeras restrições às garantias dos migrantes, revogou outro Decreto sobre o tema, com disposições ainda mais 
duras e discriminatórias. O Decreto 7.967 de 18 de setembro de 1945, revogado pelo antigo Estatuto, deliberava sobre a imigração e a colonização, e estabelecia em seu art. $2^{\circ}$ que a admissão dos imigrantes deveria atender "à necessidade de preservar e desenvolver, na composição étnica da população, as características mais convenientes da sua ascendência europeia, assim como a defesa do trabalhador nacional". Em uma breve análise do trecho colacionado pode-se constatar o pensamento predominante sobre a questão da migração, com critérios preconceituosos e excludentes. Além disso, assim como as legislações anteriores sobre o tema, a questão repousava precipuamente sobre a capacidade para o trabalho.

Importante ressaltar que um dos significativos passos rumo a esta maior proteção foi a promulgação do decreto presidencial $\mathrm{n}^{\circ} 8.501$ em agosto de 2015, que ratificou a Convenção das Nações Unidas para a Redução dos Casos de Apátrida, de 1961. A Lei 6975 de 2009 também trouxe grandes contribuições ao promulgar o Acordo sobre Residência para os estrangeiros do Mercosul, Bolívia e Chile; bem como a Lei 9.474, de julho de 1997, ao definir os mecanismos para a implementação do Estatuto dos Refugiados de 1951.

De acordo com a revista Exame em julho de 2015, cerca de $0.9 \%$ da população no Brasil é composta por imigrantes, tendo o país acolhido cerca de 1.847.274 imigrantes regulares até março de 2015. Além disso, segundo dados da Polícia Federal, no ano de 2016 houve 126.258 novos registros de estrangeiros, evidenciando a importância do presente estudo e de uma nova legislação condizente com a urgência da questão. Além disso, segundo a Organização Internacional para as Migrações - OIM, as migrações na América Latina deverão continuar subindo nos próximos anos, haja vista um cenário mais restritivo na Europa e nos demais países desenvolvidos.

De outro norte Carmem Lussi (2015) considera que a migração é relevante como fenômeno humano, apresentando-se como um fator intrínseco do desenvolvimento da sociedade, e não como um caso emergencial a ser registrado tão somente. Os deslocamentos migratórios precisam de uma abordagem preocupada com as situações de médio e longo prazo, desde suas apresentações políticas as programações de ações para contextos locais.

Sob este aspecto, as pesquisas sobre as condições de migração no Brasil e seus aspectos subjetivos são fartas na academia, onde o tema é constantemente abordado. No entanto, principalmente em virtude de sua recente aprovação no Congresso Nacional, são escassos os estudos realizados sobre a nova Lei de Migrações e suas implicações, de forma que mostra-se imprescindível a análise sobre o tema e as principais alterações em relação à legislação anterior.

\section{Estatuto do Estrangeiro}

O estatuto do estrangeiro, sancionado em 1980, surgiu em um contexto de ditadura militar no Brasil, e de Guerra Fria no âmbito mundial, que considerava o estrangeiro uma ameaça à segurança nacional, um potencial criminoso. Neste sentido, Sprandel (2015) destaca que essa ameaça representada pelos estrangeiros, por quem vem de fora, estava intrinsecamente relacionada à ameaça interna, aos subversivos que não aceitavam o sistema ditatorial, os "inimigos internos".

Assim, no art. $2^{\circ}$ da Lei 6815/80, pode-se visualizar o intuito protecionista do Estatuto do Estrangeiro, que assim dispoe: 
Art. $2^{\circ} \mathrm{Na}$ aplicação desta Lei atender-se-á precipuamente à segurança nacional, à organização institucional, aos interesses políticos, sócio-econômicos e culturais do Brasil, bem assim à defesa do trabalhador nacional.

Ao dispor entre as principais diretrizes da política migratória a segurança nacional e a defesa do trabalhador nacional, o Estatuto do Estrangeiro reforça o pensamento predominante, e aloca o migrante como uma possível ameaça nacional. Ainda sobre esta questão, importante frisar o conceito de Segurança Nacional na ocasião da promulgação do Estatuto do Estrangeiro, fornecida (?) pelo Decreto Lei 314, de 13 de março de 1967, que assim estabelecia:

Art. $3^{\circ}$ A segurança nacional compreende, essencialmente, medidas destinadas à preservação da segurança externa e interna, inclusive a prevenção e repressão da guerra psicológica adversa e da guerra revolucionária

ou subversiva.

$\S 1^{\circ}$ A segurança interna, integrada na segurança nacional, diz respeito às ameaças ou pressões antagônicas, de qualquer origem, forma ou natureza, que se manifestem ou produzam efeito no âmbito interno do país.

$\S 2^{\circ}$ A guerra psicológica adversa é o emprego da propaganda, da contrapropaganda e de ações nos campos político, econômico, psicossocial e militar, com a finalidade de influenciar ou provocar opiniões, emoções, atitudes e comportamentos de grupos estrangeiros, inimigos, neutros ou amigos, $\begin{array}{lllll}\text { contra a } & \text { consecução nacionais. }\end{array}$

$\S 3^{\circ}$ A guerra revolucionária é o conflito interno, geralmente inspirado em uma ideologia ou auxiliado do exterior, que visa à conquista subversiva do poder pelo contrôle progressivo da Nação.

No conceito de Segurança Nacional, preconizado pelo Decreto 314/67, e priorizado na política migratória do antigo Estatuto do Estrangeiro, resta evidente que busca-se afastar a influência de ideias e convicções dos que poderiam representar uma ameaça ao Estado. Assim, o Estatuto do Estrangeiro reflete esse conceito do estrangeiro como potencial criminoso e subversivo, como reflexo do contexto político nacional e internacional predominante.

Esta parcela da população fica menos protegida e fragilizada a cada etapa de enrijecimento das políticas migratórias que o estado impõe. Ainda nesse ambiente o Brasil apresenta em sua estrutura política e geográfica e em sua amplitude territorial um crescente acolhimento aos imigrantes. Conforme Baeninger (1996) destaca, os fluxos migratórios percorrem distintas fases, com fundamentos motivacionais e em períodos distintos e vinculados a conjunturas econômicas internas e globais.

Sprandel (2015), em sua análise sobre o contexto em que o Estatuto do Estrangeiro foi publicado, destaca ainda que esta concepção do estrangeiro preconizada na antiga norma sempre esteve presente nas demais legislações anteriores sobre o tema, ou facilitando a expulsão dos indesejáveis, ou dificultando a entrada. Foram diversos os decretos legislativos anteriores que barravam a imigração de nativos da África e da Ásia, ou de ciganos, de maiores de 60 anos, mendigos, vagabundos, dentre outros. Neste sentido, destaca-se que além do aspecto da Segurança Nacional, a proteção ao trabalhador nacional ou incentivo à outras políticas relacionadas ao trabalho também sempre estiveram presentes nas legislações sobre migração, a exemplo do disposto no final do art $2^{\circ}$ da Lei 6815/80. 
Em seu estudo sobre a posição do imigrante no Brasil ao longo da história Giralda Seyferth (2008) evidencia que a imigração sempre esteve relacionada à questões trabalhistas, além da preponderância de questões étnico-raciais. Assim, o Estatuto do Estrangeiro representa a continuidade das políticas até então adotadas, associado ao pensamento de um regime ditatorial e nacionalista.

\section{Principais Inovações}

São muitos os aspectos formais e materiais que foram modificados com a nova lei, de forma que não se pretende abarcar exaustivamente todas as alterações. Outrossim, intenta-se analisar as principais modificações consoantes à proteção dos direitos do imigrante e garantia dos direitos humanos. Em um cenário de instabilidade política e adoção de diversas medidas de supressão de direitos sociais, a análise na nova Lei de Migrações se faz necessária, tanto pela urgência que o tema exige no âmbito mundial, quanto pelas particularidades no Brasil neste momento de grandes mudanças, nem sempre favoráveis para a população.

No cenário global contemporâneo as fronteiras territoriais se dissolvem com maior facilidade, por força e integração política e social voltadas ao imigrante. Dessa forma no Brasil, o atrativo para o imigrante pode percorrer a trajetória que vai desde a econômica, se considerarmos países que lançam público em busca de melhores condições de sobrevivência, já que nesse contexto o país recebe pessoas de países em crises e guerras. E de imigrantes que procuram o Brasil por motivos diversos. Atualmente as principais razões que impulsionam a entrada de imigrantes permanece vinculada a perspectiva econômica.

Sancionada no dia 24 de maio de 2017, a Nova lei de Migração sofreu diversos vetos do então Presidente da República Michel Temer, mesmo após as muitas alterações já realizadas no Congresso Nacional. Ao todo foram vetados 18 trechos do texto, que apresentavam questões relevantes para a agenda de políticas públicas sobre o tema. Dentre os trechos vetados, um dos principais foi o veto ao $\$ 2$ do art. $4^{\circ}$, que permitia ao imigrante exercer cargo, emprego ou função pública, exceto aqueles reservados aos brasileiros natos, e que havia sido alvo de protestos por parte de alguns setores da sociedade. ${ }^{3}$

Além disso, o $\$ 2^{\circ}$ do art. $2^{\circ}$, que tratava da livre circulação de povos indígenas em terras tradicionalmente ocupadas também sofreu veto presidencial, com a alegação de que o dispositivo feria a defesa do território Nacional, estabelecido constitucionalmente. A anistia a imigrantes que ingressaram no país antes de 06 de julho de 2016 e que realizassem o pedido até um ano após o início da nova lei também saiu do texto final, bem como a revogação das expulsões decretadas antes de 05 de outubro de 1988.

A mudança de nomenclatura de estrangeiro para imigrante na nova lei também merece destaque, visto que as duas palavras possuem significados diferentes. Segundo Seyferth, "estrangeiro é o indivíduo natural de outro país ou, na versão substantiva, aquele que não é natural, nem cidadão, do país onde se encontra", e remete a um aspecto geral, ao passo que " a imigração tem sido qualificada justamente pela entrada de indivíduos ou grupos num país estrangeiro com intenção de ali restabelecer sua residência" (p. 3, 2008).

No que tange ás inovações da nova lei, a principal delas foi a própria alteração da perspectiva do Estado e da legislação com relação ao migrante, que não mais é visto sob o

\footnotetext{
${ }^{3}$ Ainda que isolados, foram realizados alguns registros de protestos no Brasil contra a nova Lei de Migração. Disponível em: http://www1.folha.uol.com.br/cotidiano/2017/05/1884627-movimento-contrario-a-lei-demigracao-faz-protesto-na-av-paulista.shtml
} 
âmbito estrito da segurança nacional, mas passa a ocupar a condição de sujeito de direitos, claramente visualizada no art. $3^{\circ}$ da Lei $13445 / 17$, bem como em seu art. $4^{\circ}$, caput, que assim dispõe:

Art. 4ํㅜ Ao migrante é garantida no território nacional, em condição de igualdade com os nacionais, a inviolabilidade do direito à vida, à liberdade, à igualdade, à segurança e à propriedade, bem como são assegurados

Este dispositivo da lei de Migração estende aos imigrantes os direitos fundamentais já previstos aos cidadãos nacionais, conforme disposto na Constituição Federal, no caput do art. $5^{\circ}$, que assim estabelece:

Art. $5^{\circ}$ Todos são iguais perante a lei, sem distinção de qualquer natureza, garantindo-se aos brasileiros e aos estrangeiros residentes no País a inviolabilidade do direito à vida, à liberdade, à igualdade, à segurança e à propriedade.

Neste sentido, Rothemburg (2014, p.05) destaca que os direitos fundamentais são universais, porquanto inerentes à própria condição humana. Destaca ainda que as diferenças tem o condão de reforçar a necessidade desses direitos, reconhecendo os direitos fundamentais na própria diversidade. Outrossim, ainda que dotados desta universalidade, a internacionalização e estabelecimento de uma norma legal que disponha especificamente sobre os direitos fundamentais para os imigrantes é de profunda importância, visto que ressalta e reforça sua aplicação, ainda que no âmbito formal

Em um aspecto geral, houve também uma desburocratização do processo para a concessão de vistos, conforme princípio estabelecido no art. $3^{\circ}$, inciso $\mathrm{V}$, que determina a "promoção de entrada regular e de regularização documental". Ademais, a autorização para residência prevista nos arts. 30 a 36 também apresentaram critérios inovadores, como a possibilidade de autorização para o imigrante que tenha oferta de trabalho no país, ou que seja menor de outro país, desacompanhado ou abandonado e que se encontre no território nacional.

Outra modificação importante diz respeito a expressa manifestação que estabelece o repúdio e prevenção a xenofobia, ao racismo, e quaisquer outras formas de discriminação, conforme art 3, inciso II da nova lei. Além disso, ainda no art. 3, o inciso II também inovou ao estabelecer o fim da criminalização da imigração, ou seja, ninguém modera ser punido apenas por estar em situação irregular no pais.

No que tange aos direitos sociais, o inciso VIII do art. $4^{\circ}$, representou grande avanço, ao estipular o "acesso a serviços públicos de saúde e de assistência social e à previdência social, nos termos da lei, sem discriminação em razão da nacionalidade e da condição migratória", alem do inciso IX do mesmo artigo, que determina "amplo acesso à justiça e à assistência jurídica integral gratuita aos que comprovarem insuficiência de recursos".

Assim, a nova lei estabelece o direito dos imigrantes de acesso aos principais direitos sociais previstos no Brasil, principalmente o acesso a seguridade social e assistência jurídica integral, ainda que estes direitos não tenham, muitas vezes, aplicabilidade plena sequer aos cidadãos nacionais. Sob este aspecto, Rothenburg (2014, p. 243) ressalta que o direito a assistência jurídica, previsto no art. 5, LXXIV, da Constituição federal não abarca apenas a 
assistência judiciaria, mas também a assistência jurídica preventiva, bem como os meios que a viabilizem, como acesso a Defensoria Pública e isenção de custas.

Além disso, foi prevista também a livre associação, inclusive para participação sindical, conforme estabelecido no art. $4^{\circ}$, inciso VII da nova lei. Dessa forma, resta garantida juridicamente um dos corolários do princípio da liberdade, e meio para garantia da dignidade humana, visto que o direito de associação está intrinsecamente ligado à organização para proteção dos direitos estabelecidos, inclusive proteção nas relações de trabalho.

Dessa feita, evidencia-se que houve uma maior proteção do imigrante na nova lei, tanto com relação aos direitos civis, com a garantia de liberdades individuais, tanto no âmbito dos direitos sociais, com a previsão de medidas que visam a diminuição da desigualdade e efetivação da dignidade do imigrante.

\section{Conclusão}

Todas as constatações a respeito das inovações e perspectivas da nova Lei de Migrações, indicam fortemente a relevância de maiores discussões e reflexões sobre os processos migratórios, onde o Brasil por ser um país de grande recepção, amplie dentro de suas políticas públicas a preservação dos direitos inerentes ao ser humano para os migrantes.

Todos os aspectos formais e materiais que foram modificados na nova lei, revelam uma atualização dos cidadãos nacionais ou estrangeiros, mesmo com a interferências negativa do presidente da república Michel Temer através de vetos presidenciais. Esta problemática em questão fica em paralelo com as ampliações e renovações de políticas e ações voltadas a nova situação, onde o Brasil passa a receber milhares de grupos de imigrantes e refugiados em meio a uma crise econômica e financeira. Através dos pressupostos apresentados se faz necessário tomar em conta os fluxos de migração, as necessidades que os envolvem e de que maneira o Brasil pode ampliar seu escopo para dar conta dos direitos humanos dos migrantes e suas famílias, garantindo o desenvolvimento e democracia.

Fica o desafio de transformar as perspectivas que a lei permite em programas e práticas sociais condizentes com a proposta, evidenciando a constante luta contra os conflitos e antagonismos e contradições. Diante deste cenário podemos ainda expressar que é recente para avaliarmos os impactos da Nova Lei neste sentido, o presente estudo não possui a prerrogativa de esgotar a análise sobre o tema, mas favorecer para as futuras pesquisas e contemplações.

\section{Referências}

ARANTES, J. T.. O panorama da imigração no Brasil. Revista Exame. Publicação em 07 de julho de 2015. Disponível em: http://exame.abril.com.br/brasil/o-panorama-daimigracao-no-brasil/.

BAPTISTA, R.; VILAR, I. Projeto da nova Lei de Imigração segue para sanção presidencial. Senado Notícias. Publicado em 18 de abril de 2017. Disponível em http://www12.senado.leg.br/noticias/materias/2017/04/18/projeto-da-nova-lei-de-migracaosegue-para-sancao-presidencial. Acesso em 29 de abril de 2017. 
CAMPOS. M. B. Características demográficas e a voluntariedade da migração. REMHU, Rev. Interdiscip. Mobil. Hum. vol.23 no.45 Brasília jul./dez. 2015.

KENICKE, P. H. G. O estatuto do estrangeiro e a lei de migrações: entre a doutrina da segurança nacional e o desenvolvimento humano. Dissertação (Mestrado em Direito do Estado) - Universidade Federal do Paraná, Curitiba, 2016.

LUSSI. C. Políticas públicas e desigualdades na migração e refúgio. Psicol. USP vol.26 no.2 São Paulo maio/ago. 2015.

ONU BRASIL. Migração entre países latino-americanos deve continuar subindo, diz OIM. Disponível em https://nacoesunidas.org/migracao-entre-paises-latino-americanos-devecontinuar-subindo-diz-oim/. Acesso em 01/05/2017.

PAZ, C. E. Lei de migração coloca o Brasil na vanguarda da defesa dos imigrantes. Revista Consultor Jurídico. 18 de abril de 2017, 15h 28. Disponível em: http://www.conjur.com.br/2017-abr-18/lei-migracao-coloca-brasil-vanguarda-defesaimigrantes.

POLÍCIA FEDERAL. Registro de estrangeiros. Ministério da Justiça e Segurança Pública. Disponível em: http://www.pf.gov.br/imprensa/estatistica/estrangeiros . Acesso em 01/05/2017.

ROTHENBURG, W. C. Direitos Fundamentais. Coordenacao Andre Ramos Tavares, Jose Carlos Francisco. São Paulo: Método, 2014.

SEYFERTH, Giralda. Imigrantes, estrangeiros: a trajetória de uma categoria incomoda no campo político. Trabalho apresentado na Mesa Redonda Imigrantes e Emigrantes: as transformações das relações do Estado Brasileiro com a Migração. 26ª Reunião Brasileira de Antropologia, realizada entre os dias 01 e 04 de junho de 2008, Porto Seguro, Brasil. Disponível em: $<$ http://www.abant.org.br/conteudo/ANAIS/CD_Virtual_26_RBA/mesas_redondas/trabalho s/MR\%2012/giralda\%20seyferth.pdf $>$.

SILVA, C. R. Migração não pode ser pensada como questão de segurança nacional, diz pesquisadora. Jornal Brasil de Fato. Publicação em 22 de abril de 2016. Disponível em https://www.brasildefato.com.br/2016/04/22/migracao-nao-pode-ser-pensada-como-questaode-seguranca-nacional-diz-pesquisadora/. Acesso em 01/05/2017.

SPRANDEL, M. A. Migração e crime: a Lei 6.815, de 1980. REMHU, Rev. Interdiscip. Mobil. Hum. vol.23 nº.45 Brasília Jul/dez. 2015.

TEIXEIRA, E.; BRAGA, A. M. C.; BAENINGER, R. Migrações: Implicações passadas, presentes e futuras. São Paulo: Cultura Acadêmica, 2012.

PACHECO, Tânia. "Teatro alternativo em 70: a luz no final do túnel”. Em 20 anos de resistência.

\section{Legislação}


Lei 6.815, de 19 de agosto de 1980. Define a situação jurídica do estrangeiro no Brasil, cria $o$ Conselho Nacional de Imigração. Disponível em http://www.planalto. gov.br/ccivil_03/Leis/L6815.htm.

Lei 9.474, de 22 de julho de 1997. Define mecanismos para a implementação do Estatuto dos Refugiados de 1951. Disponível em http://www.planalto.gov.br/ccivil_03/leis/L9474.htm.

Decreto 7.967 de 18 de setembro de 1945. Dispõe sobre a Imigração e Colonização, e dá outras providências. Disponível em http://www.planalto.gov.br/ccivil_03/decreto-lei/19371946/Del7967.htm.

Decreto $n^{\circ} 6.975$ de 07 de outubro de 2009. Promulga o Acordo sobre Residência para Nacionais dos Estados Partes do Mercado Comum do Sul-Mercosul, Bolívia e Chile. Disponível em http://www.planalto.gov.br/ccivil_03/_ato20072010/2009/decreto/d6975.htm.

Decreto $\mathrm{n}^{\circ}$ 8.501, de 18 de agosto de 2015. Promulga a Convenção para a Redução dos Casos de Apátrida, firmada em Nova Iorque, em 30 de agosto de 1961. Disponível em http://www.planalto.gov.br/ccivil_03/_Ato2015-2018/2015/Decreto/D8501.htm.

Decreto Lei 314, de 13 de março de 1967 